\title{
NANOTECNOLOCIA O OLHAR DA CIÊNCIA SOBRE A TOXICIDADE E OS POTENCIAIS RISCOS DESSES PRODUTOS
}

\author{
NANOTECHNOLOGY: THE SCIENCE'S VIEW ON TOXICITY \\ AND THE POTENCIAL RISKS OF THESE PRODUCTS
}

Luisa Lauermann Lazzaretti /ulilazzaretti@gmail.com

Especialista em Gestão Empresarial pela ESPM (Porto Alegre/Brasil).

Graduada em Direito pela Universidade Feevale (Novo Hamburgo/Brasil).

Bolsista de Iniciação Científica da Universidade Feevale (Novo Hamburgo/Brasil).

\section{Haide Maria Hupffer haide@feevale.br}

Doutora em Direito pela Universidade do Vale do Rio dos Sinos (São Leopoldo/Brasil).

Professora na Universidade Feevale (Novo Hamburgo/Brasil). 


\section{RESUMO}

Produtos e aplicações com nanotecnologia emergem no mercado consumidor devido à infinita possibilidade de exploração, pela multiplicidade de usos, por serem mais eficientes e pela redução dos custos de produção. Contudo, não há informações científicas suficientes para precisar os potenciais riscos ligados ao uso de nanotecnologia para a saúde humana e o meio ambiente, gerando incertezas quanto ao seu uso. $O$ objetivo desse estudo é observar se os artigos científicos disponibilizados na base de dados da Web of Science discutem riscos que os produtos nanoestruturados podem causar à saúde humana e ao meio ambiente. $O$ método utilizado é o dedutivo. A técnica de pesquisa é a revisão bibliográfica realizada na base de dados da Web of Science. A análise do conteúdo é realizada pela busca isolada e do cruzamento das seguintes palavras-chaves: nanotecnologia, nanotoxicidade, risco e nanopartículas, nos idiomas inglês e português. Delimitou-se o prazo de cinco anos (2013-2017). A pesquisa observou um predomínio de trabalhos relacionados com síntese, estabilidade, características de nanopartículas e nanotecnologia. Observou-se um pequeno número de estudos que analisam a toxicidade de nanopartículas no médio e longo prazo, bem como no clico de vida desses nanomateriais, indicando que esses produtos são lançados no mercado sem as devidas pesquisas para acompanhar os riscos desta nova tecnologia que é permeada pela incerteza científica.

Palavras-chave: Nanotecnologia. Toxicidade. Risco.

\section{ABSTRACT}

Products and aplications with nanotechnology rise in the consuming market due the infinite possibilities of exploration, for the multiplicity of usages, for being more effective and the reduction in costs of production. Althoug, insuficient information is provided to determine the potential risks linked to the use of nanotechnology for human health and the enviroment, generating uncertainties regarding their use. The purpose of this study is to observe if the scientific papers available in the Web of Science database, discuss the risks of the nano-structured products to the human health and to the enviroment. The method to be utilized is a deductive approach. The reasearch technique is the bibliographic review realized in the Web of Sience database. The analysis of the matter is realized for the isolated search for the intersection of the following words: nanotechnology, nanotoxicity, risk, nanoparticles, available in English and Portuguese versions. Has been attached a five years time limit (2013-2017). The survey noted a predominance of works related to synthesis, stability, features of nanoparticles and nanotechnology. The small number of studies that analyze the toxicity of nanoparticles in medium and long terms, just as the nanomaterials life cycle, point that nanotechnology products are launched in the market without research to monitor the risks of this new technology wich is permeaded by scientific doubt.

Keywords: Nanotechnology. Toxicity. Risk. 


\section{INTRODUÇÃo}

A produção de produtos e aplicações com nanopartículas está avançando rapidamente sem que se tenha certeza científica dos seus efeitos na saúde humana e no meio ambiente. A nanotecnologia é reconhecida como a quarta revolução industrial pelo alto potencial mercadológico e pelas possibilidades de sempre novas inovações. Ela já está presente em praticamente todas as áreas. Setores como cosméticos, fármacos, petróleo, alimentação, eletrônicos, construção civil, plásticos, química, agricultura, higiene pessoal, medicina, entre outros já estão no cotidiano da vida das pessoas. 0 crescimento de produtos com nanomateriais também representa a ampliação significativa da exposição humana e do meio ambiente sem que se tenham respostas sobre os riscos e perigos dessa nova tecnologia.

O problema de pesquisa indaga se é possivel dizer que há uma preocupação de pesquisadores (que publicam resultados de pesquisas na Web of Science) sobre riscos da exposição dos seres humanos a produtos e aplicações com nanotecnologia, bem como o ciclo de vida desses nanomateriais, a biodisponibilidade e os efeitos tóxicos. Para responder ao problema de pesquisa elege-se como objetivo geral observar se os artigos científicos disponibilizados na base de dados da Web of Science nos últimos cinco anos (2013-2017) discutem riscos que materiais nanoestruturados podem causar à saúde humana e ao meio ambiente.

O método escolhido como linha de raciocínio para abordar o problema da pesquisa é o método dedutivo e a análise de conteúdo, com utilização de revisão bibliográfica na base de dados da Web of Science. Para a análise de conteúdo foram utilizadas as palavras-chave: nanotecnologia, nanotoxicidade, nanopartículas e risco, nos idiomas inglês e português.

O artigo foi dividido em três partes: inicialmente buscar-se-á descortinar o mundo da nanotecnologia, compreendendo o seu conceito, as principais aplicações, de que mercado está se falando e suas principais potencialidades. Na sequência, analisar-se-á o conceito de toxicologia e nanotoxicologia e o que a literatura compreende como risco e perigo. Depois, indicar-se-á a metodologia e como será realizada a pesquisa na base de dados da Web of Science. Por fim, apresentar-se-ão os resultados da pesquisa de análise de conteúdo com discussão qualitativa, alguns artigos científicos que discutem os riscos e a toxicidade de alguns produtos com nanotecnologia.

\section{NANOTECNOLOGIA: COMPREENDENDO O CONCEITO, meRCADO E sUAS POTENCIALIDADES}

Materiais em escala manométrica vêm sendo usados indiretamente há séculos, mesmo com as dificuldades de manipulação, devido às limitações de equipamentos, conhecimento e tecnologia 
apropriados. Desde tempos remotos, o homem tem utilizado nanopartículas, como os antigos artífices que usavam argila para elaboração de objetos domésticos ou, ainda, aqueles que incorporavam a vidros partículas finamente divididas para a criação de vitrais coloridos, empregados em catedrais europeias (MEDEIROS; MATTOSO, 2006, p. 16).

O termo nanotecnologia foi criado, em 1974, por Norio Taniguchi, da Universidade de Tóquio, ao descrever a síntese de materiais em escala nanométrica. Contudo, a origem dos estudos nessa área remete a Richard Feynman que, em 1959, com seu livro "Thre's Plenty of Room at the Bottom", apresentou o conceito em um encontro da Sociedade Americana de Física (ACT, 2005, p. 6). Esse cientista propôs uma inovação muito importante e poderosa na química: a manipulação direta de átomos individuais, resultando na produção de dispositivos úteis para todos os campos do conhecimento. Nesse encontro, ele também sugeriu escrever na cabeça de um alfinete os 24 volumes da Enciclopédia Britânica, contudo isso ainda não seria possível, pois não havia dispositivos disponíveis na época. Entretanto, a nanotecnologia somente se popularizou com os estudos de Eric Drexler, em 1986, com a publicação do livro "Engines of Creation: The Coming Era of Nanotechnology" (ACT, 2005, p. 6).

Para a organização Royal Society \& Royal Academy of Engineering (RSRAE, 2004, p. 5), a nanociência é definida como o estudo do fenômeno de manipulação dos materiais em nível atômico, molecular e macromolecular, onde as propriedades desses materiais diferem significativamente de suas características em escala maior.

Segundo U.S National Nanotechnology Initiative (NNI), a nanotecnologia é a capacidade de estudar, compreender e sintetizar materiais em dimensões entre um e 100 nanômetros, possibilitando novas utilizações para esses materiais (SHATKIN, 2013, p. 7).

A National Science Foudation (NSF) conceitua a nanotecnologia de forma mais ampla, pois cita que a manipulação dos átomos pode dar-se abaixo de um nm, ou, ainda, acima de 100 nm, principalmente nanopartículas poliméricas de dimensões entre 200 a 300 nm. Essas partículas se destacam devido às interações intermoleculares, sendo seu uso destacado nas áreas farmacêuticas e médicas (ABDI, 2013).

Em 2011, a European Commission (EC) divulgou recomendações para a descrição de nanomateriais. Segundo esse documento, um nanomaterial é aquele de origem natural, incidental ou manufaturado que contém partículas em estado não ligado, aglomerado ou agregado, com no mínimo 50\% das partículas entre $100 \mathrm{~nm}$. Entretanto, quando necessário, em face de necessária precaução ao meio ambiente, à segurança, à saúde ou à competitividade, esse limite pode ser alterado para um limiar entre 1 e 50\% do material composto com partículas de até 100 nm, ou seja, a classificação em nanomaterial será baseada unicamente no tamanho da partícula. Para alcançar essa definição atual pela European Commission, foram 
necessários mais de dois anos de discussão entre os agentes da Comissão, além da realização de uma consulta pública. Nesse mesmo sentido de excepcionalidade é o conceito definido pela European Medicine Agency que consideram como nanotecnologia estruturas menores de 1.000 nanômetros de diâmetro com propriedades específicas diferentes da matéria em escala maior (ABDI, 2013, p. 12).

Já a fundação independente International Risk Governance Council (IRG) recomenda o uso da definição de nanotecnologia e de nanomateriais estabelecida pela International Organization for Standardization Technical Committee (ISO/TC) 229 de 2005 e a Techinical Specifications (ISO/TS) 27687 de 2008 para serem usados em alimentos e cosméticos (IRG, 2009).

O Brasil, após os trabalhos realizados pelo Fórum de Competitividade em Nanotecnologia, elaborado pelo Ministério do Desenvolvimento, Indústria e Comércio Exterior - MDIC -, no seu GT Marco Regulatório, adotou como conceito de nanotecnologia o definido pelo ISO TC 229 de 2005(ENGELMANN; HOHENDORFF; FROHLICH, 2015).

A maioria dos países da União Europeia, como Bélgica, França e Dinamarca, utilizam, basicamente, a definição da recomendação da European Commission, contudo, esses países consideram como nanomateriais as substâncias intencionalmente manufaturadas em escala nanométrica, diferindo, assim, da recomendação da European Commission, pois, por essa recomendação, considera-se nanomateriais os de origem natural e os acidentalmente sintetizados. Já alguns países da Ásia, como İndia, Japão e Malásia, utilizam a definição de nanotecnologia definida pela ISO/TC 229, a mesma usada pelo Brasil (RAUSCHER; ROBBEN, 2014).

Nos Estados Unidos da América, não há uma definição juridicamente aceita de nanomaterial. 0 órgão governamental American Food and Drug Administration (FDA) realizou, em 2011, um guia para a indústria no qual definiu como nanomateriais os materiais sintetizados ou produtos finais que tenham pelo menos uma das dimensões entre 1 a 100 nm. Em 2010, esse órgão publicou um Manual de Políticas e Procedimentos (MAPP50159) com o objetivo de identificar produtos baseados em nanotecnologia e catalogá-los em uma base de dados específica para nanotecnologia. Nesse documento, estabeleceu-se que nanomateriais seriam quaisquer materiais com no mínimo uma de suas dimensões menor do que 1.000 nm (RAUSCHER; ROBBEN, 2014).

Para exemplificar, em relação aos nanocosméticos, verificam-se duas importantes definições elencadas na sequência. A organização de regulamentação de cosméticos Internacional Cooperation Cosmetic Regulation (ICCR) é um grupo que reúne autoridades dos Estados Unidos da América, Japão, União Europeia e Canadá. Para esse grupo, a substância, para ser considerada um nanomaterial, deve ser insolúvel, intencionalmente sintetizado, com dimensões entre 1 a 100 nm após a manipulação, e ser 
estável e persistente nos meios biológicos, sendo capaz de interagir com os sistemas biológicos. Pela nova proposta de definição da Europea Union Cosmetic Product Regulation, são considerados nanomateriais os materiais insolúveis ou biopersistentes, fabricados intencionalmente com uma ou mais dimensões externas ou com uma dimensão interna na escala de 1 a 100 nm (ENGELMANN; HOHENDORFF; FROHLICH, 2015, p. 25-26).

Salienta-se que não há consenso quanto ao conceito de nanotecnologia, sendo encontradas diferentes acepções que têm em comum a definição do tamanho da partícula e as diferentes propriedades que esses materiais adquirem nessa escala. Essa ausência de consenso, quanto à definição de nanotecnologia e nanomateriais e, também, das características relevantes a serem consideradas para classificar uma partícula como sendo um nanomaterial, demonstra o desconhecimento que cercam as nanotecnologias, causando incertezas e insegurança, tanto no meio acadêmico quanto na população em geral (SHATKIN, 2013).

Analisando os diferentes conceitos de nanotecnologia e nanomateriais, verifica-se que, em comum, todas as definições utilizam a mesma gama de tamanho entre 1 a 100nm. Outra característica importante a ser destacada é a solubilidade das nanopartículas, porque, se a partícula não é solúvel, há maior probabilidade de bioacumulação, enquanto que as partículas solúveis tendem a ser biodegradadas. Ainda, outro critério importante para a classificação em nanotecnologia é a capacidade de agregação ou aglomeração que é a capacidade da partícula se combinar com outras, aumentando o tamanho, podendo, com isso, ocasionar novas características físico-químicas. Salienta-se que grande parte das definições estudadas acima considera como nanopartículas aquelas manipuladas pela ação humana (ENGELMANN; HOHENDORFF; FROHLICH, 2015).

Nessa linha é o trabalho de Singh (2017) que, em uma revisão bibliográfica, analisou estudos inovadores relacionados com a nanotecnologia em áreas como a biomedicina, alimentos, química, entre outras. Nesse trabalho, ele verificou que a ampla definição de nanotecnologia, também, cria dificuldades tanto para o inventor quanto para o examinador na classificação de novas patentes. Então, um novo pedido de patente pode ser classificado, equivocadamente, como microescala ou como pontos quânticos, para descrever uma invenção nanotecnológica, ao invés de utilizar o termo nanotecnologia, devendo tanto o examinador de novas patentes quanto o inventor tomarem precaução ao utilizar o termo correto de nanotecnologia (SINGH, 2017).

As nanopartículas são classificadas, conforme sua composição química, em três grandes grupos: as nanopartículas inorgânicas, as orgânicas e as híbridas, sendo a categorização mais utilizada no meio acadêmico. No grupo das inorgânicas, destacam-se os óxidos metálicos, como dióxido de titânio, óxido de 


\section{CONHECIMENTO

ferro; as nanopartículas dos metais de transição, como o ouro e a prata; e os pontos quânticos compostos, principalmente, por cádmio e selênio. No grupo dos orgânicos, os principais representantes são as nanopartículas formadas pelos átomos de carbono, como o fulereno, os grafenos e as nanofibras de carbono, além dos lipossomas, nanoemulsões, dentre outras. Já os nanomateriais híbridos são formados por dois tipos de nanocomponentes, com funções complementares ou coesas entre si, como exemplo elenca-se a conjugação de biomoléculas a nanopartículas metálicas e a associação de nanomoléculas orgânicas a matrizes nanopoliméricas com a finalidade de melhorar as propriedades térmicas, mecânicas e ópticas (COSTA, 2015).

As mais importantes partículas nanoestruturadas descritas na literatura são as de óxido metálicas, como ferro, ouro e prata, entre outros metais utilizados nos mais variados segmentos da indústria, como sensores eletroquímicos e biossensores, administração de fármacos através da aplicação de um campo magnético, dentre outras utilidades. Ainda, há as nanopartículas poliméricas como as micelas, os dendrímeros e a quitosana, importantes como meios de transporte de agentes terapêuticos, uma vez que sua estrutura pode ser modificada quimicamente, sendo bastante utilizadas em terapias contra 0 câncer e em ressonância magnética. Outra classe que se destaca na liberação de fármacos e agentes terapêuticos lipofílicos são as nanopartículas lipídicas sólidas, conhecidas, também, como lipoesferas ou nanoesferas lipídicas sólidas, apresentando alta estabilidade em meio biológico e na temperatura corporal, devido ao seu núcleo rígido e a camada externa de fosfolipídios (FARAJl; WIPF, 2009).

Ademais, destacam-se os nanocristais que são empregados para aumentar a solubilidade de moléculas pouco solúveis em meio biológico, utilizadas, principalmente, como "nanocarreadores de fármacos pelas vias oral e parenteral" (DIMER, 2013, p. 1521). Existem, também, os pontos quânticos, conhecidos no meio acadêmico como quantum dots, os quais são nanopartículas semicondutoras, luminescentes, quando estimuladas por fótons ou elétrons, fotoestáveis e com tendência a manter sua fluorescência, possibilitando a sua utilização em diversos segmentos, como telecomunicações, computação e, principalmente, na área biomédica, como marcadores de vírus e tumores (PINGE-FILHO, 2012). Outrossim, tem-se os nanotubos de carbono como os principais representantes dos nanomateriais. Eles sobressaem-se na utilização devido à multiplicidade de aplicações por causa de suas características de alta resistência, elétricas e térmicas, consistindo de lâminas de grafeno aneladas, formando um cilindro com diâmetro próximo de um nm e cavidade oca (ZARBIM, 2007).

Importante registrar que, até o começo da década de 80, não se observaram muitos avanços em estudos que empregassem a nanotecnologia, pois não existiam equipamentos que permitissem a sua manipulação, como os "microscópios de varredura por sonda (SPM), de varredura por tunelamento 
(STM), de campo próximo (NFM) e de força atômicas (AFM)", importantes para medir e manipular esses materiais, formando os arranjos nanométricos (MEDEIROS, PATERNO; MATTOSO, 2006, p. 16).

Essas descobertas indicavam que a nanotecnologia seria uma nova revolução científica, incentivando o governo Clinton, em 2000, a criar o "Instituto de Tecnologia da National Nanotechnology Initiative (NNI), com investimentos em torno de US\$ 495 milhões". Em 2010, mais de 60 países já possuíam pesquisas nacionais ligadas ao estudo das nanociências e nanotecnologias, sendo que o total de investimento global ultrapassava US\$ 5 bilhões (ABDI, 2010, p. 20). Em 2017, o orçamento do Governo Obama previu o investimento de US\$ 1,4 bilhão para esse mesmo Instituto, gerando um montante acumulado de investimentos na ordem de US\$ 24 bilhões desde a sua fundação (SUFIAN, 2017).

Os dados apresentados pela ABDI em 2010 no Panorama de Nanotecnologia mostram os vultosos investimentos nesse mercado. Estimava-se, na época, que em 2007 o mercado de produtos que utilizam nanotecnologia alcançaria US\$135 bilhões e deveria alcançar US\$ 693 bilhões até o final de 2012, projetava-se que em 2015 atingiria cerca de US\$2,95 trilhões. Ainda, conforme um estudo realizado pela Cientifica LTDA, em 2008, esta mostrou como se dava a distribuição do mercado mundial de nanotecnologia através dos setores de atividade, sendo que o "setor químico ocupa a maior parte do mercado com 53\%", após aparecem os "semicondutores com 34\% e a área farmacêutica", automotiva e de defesa, ocupando pequenas parcelas desse mercado (ABDI, 2010, p. 30).

Igualmente, um relatório realizado pela BBC Researche divulgado na Revista Advanced Materials \& Processes, em fevereiro de 2015, mostra projeções do mercado nanotecnológico global com projeção de aumento para o ano de 2019 em \$ 64.2 bilhões de dólares, com taxas de crescimento anuais de 19,8\%, impactando em todos os setores da economia, como o biomédico, eletrônico, energético, ambiental e farmacêutico (MARKET SPOTLIGHT, 2015). De acordo com esse relatório, o mercado dos nanomateriais, formado pelas nanopartículas e nanofilmes, que domina o mercado nanotecnológico, corresponde a $78,8 \%$ desse mercado. Com esses dados, pode-se verificar quão expressivos são os investimentos em pesquisa e desenvolvimento de novos produtos com nanopartículas, tanto públicos, pelos governos, quanto privados, pelas empresas e entidades não governamentais (MARKET SPOTLIGHT, 2015).

Devido à projeção mundial dessa nova tecnologia e para verificar a inserção no mercado consumidor de produtos que empregam nanotecnologia, o Instituto Woodrow Wilson Centerjuntamente com o projeto Emerge Nanotechnology criaram um sítio na rede mundial de computadores denominado de Nanotechnology Consumer Product Inventory (CPI), em 2005, com o objetivo de catalogar as invenções que utilizam técnicas nanotecnológicas, tornando-se uma importante fonte de indicadores da prevalência desses produtos no cotidiano da população (VANCE et al., 2015, p. 1.770). 
O trabalho realizado por Vance et al. (2015, p. 1771) analisou as invenções depositadas no sítio da CPI em sua primeira década de existência. No ano de 2011, foram listados 1.015 novos produtos, destes, ressalta-se que 489 não estão mais disponíveis para serem comercializados, sendo que apenas 500 foram comercialmente viáveis. Já, em 2015, foram acrescentadas 1.814 novas invenções, representando um aumento de 30 vezes dos produtos originalmente listados em 2005, essas mercadorias provêm de 622 empresas localizadas em 32 países. Ademais, segundo esse mesmo estudo, 34\% das invenções foram arquivadas por não estarem mais disponiveis no mercado consumidor.

No sítio da CPI, as invenções depositadas são classificadas em oito categorias, conforme o mercado consumidor disponibiliza as mercadorias. A categoria de saúde e fitness é a que possui a maior lista de produtos, correspondendo a $42 \%$, e dentro dessa categoria há destaque à subcategoria de produtos de cuidados especiais, que inclui xampus, sabonetes, loções, entre outros, compreendendo o percentual de 39\%. Esses dados reforçam o alcance que esses produtos nanoengenheirados têm na população em geral, cotidianamente. Além disso, verificou-se que as nanopartículas mais sintetizadas e comercializadas mundialmente são o dióxido de titânio, dióxido de silício e óxido de zinco. Já as nanopartículas de pratas estão presentes em $24 \%$ dos produtos depositados (VANCE et al., 2015).

Produtos com nanotecnologia são considerados a nova fronteira da era global, pois englobam uma revolução que reúne as áreas da ciência e tecnologia, provocando impactos significativos na economia, na política, no Direito, nas relações de consumo, no ambiente de trabalho, na saúde, no meio ambiente, entre outros. Isso demonstra que as nanotecnologias têm um espaço privilegiado na ciência para a transdiciplinaridade, visto que envolvem diversas áreas do conhecimento (ENGELMANN; MACHADO, 2013).

\section{NANOTOXICOLOGIA E A COMPREENSÃO dO CONCEITO de RISCO}

A toxicologia é a ciência que tem como objetivo o estudo dos efeitos adversos de agentes naturais sobre os biossistemas, tendo como enfoque o tratamento, o diagnóstico e, principalmente, a prevenção da intoxicação. Já a nanotoxicologia é um conceito novo que emergiu como uma "subdivisão da ciência toxicológica e tem como o escopo o estudo dos nanomateriais". Os primeiros trabalhos sobre a nanotoxicologia iniciaram-se em meados dos anos 2000, apresentando um aumento significativo no número de pesquisas relacionadas com a segurança e os riscos associados com a nanotecnologia (MARTINEZ; ALVES, 2013, p. 33).

Na toxicologia, o método clássico para avaliar os efeitos tóxicos de uma substância é a utilização de curvas dose-resposta para obter valores quantitativos de toxicidade. Já para a nanotecnologia, devido a 
suas características peculiares, há dificuldades de avaliar de modo exato e inequívoco a toxicidade desses materiais. 0 cerne dessa dificuldade centra-se no objeto estudado, pois, enquanto a "toxicologia realiza seus estudos a nível molecular, na nanotoxicologia, os toxicantes avaliados são nanopartículas", gerando implicações durante a análise da toxicidade. Além disso, outros fatores podem interferir na toxicidade desses materiais, como as características físico-químicas; a intensidade, frequência e o tempo de exposição; a vulnerabilidade do organismo exposto; as vias de introdução e, principalmente, a interação com os biossistemas (MARTINEZ; ALVES, 2013, p. 33-34).

Walker e Bucher (2009, p. 252) ressaltam que as características diferenciadas de aplicação dos nanomateriais na indústria podem ser uma "barreira na avaliação da toxicidade desses materiais, pois as diferentes variações de tamanho, forma, característica de superfície, como a porosidade, geram inúmeras possibilidades de aplicações de uma mesma nanopartícula". Outro fato interessante que merece ser destacado é em relação ao custo para a realização de estudos in vivo, tradicional de alguns nanomateriais disponiveis comercialmente que seria estimado em um bilhão de dólares e levaria em média de 30 a 50 anos (CHOI; RAMACHANDAN; KANDLIKAR, 2009, p. 3030).

Diante disso, surge a necessidade de explicar o conceito de risco. Esse termo está associado com o contexto social histórico de uma sociedade, baseado com o que ela considera em cada momento como normal e seguro, tendo um caráter instrumental, já que pode determinar particularidades estruturais das sociedades. É considerada por muitos especialistas como um assunto relativamente recente e típico de sociedades culturalmente avançadas, surgindo após os conceitos trazidos por Ulrich Beck em sua obra Sociedade de Risco, de 1986. Essa discussão surge em decorrência do cenário das novas tecnologias trazidas Pós-Revolução Industrial, como o desastre de Chernobyl, em 1986, as manipulações genéticas que podem estar atreladas a novas enfermidades e, sobretudo, aos avanços na área da engenharia genética, trazendo novos desafios científicos diante das incertezas científicas (HOM, 2004).

Segundo Beck (2010), a Sociedade de Risco é um conceito da modernidade reflexiva que resultou do advento da sociedade industrial, entre os séculos XX e XXI, no qual houve alteração de foco na distribuição de riquezas entre classes para a distribuição de riscos em escala mundial. Inicialmente, na sociedade industrial, prevalecia o princípio do "in dúbio pro progresso", assim, na dúvida de uma consequência negativa de uma atividade produtiva, devia-se dar continuidade ao progresso. Como corolário desse desenvolvimento, os riscos não estão mais associados ao lugar os quais foram gerados, mas sim atrelados como uma ameaça mundial em todos os níveis. Os riscos dessa sociedade, na maior parte das vezes, como elucida Beck (2010, p. 27-41), são "irreversíveis, fundamentalmente invisíveis, globalizados, transtemporais, transterritoriais e baseiam-se em interpretações causais". Para o autor, esse conceito 
está atrelado a diversos fatores, dependendo do ponto de vista do interessado (cientistas, indústria, governantes e sociedade civil), oscilando com a diversidade de valores, interesses e conhecimento científico ou anticientífico.

Importante destacar nos conceitos introduzidos por Beck (2010) que os riscos contemporâneos são ameaças universais advindas do processo produtivo e materializadas através do conhecimento científico, podendo ser aumentadas, diminuídas ou dramatizadas, conforme definições sociológicas, escolhidas, conforme aspiração do grupo de interesse. Esses riscos, oriundos da sociedade moderna são intermináveis, surgindo situações de ameaças constantes que são invisiveis e possuem uma tendência à globalização, atravessando fronteiras, não estando mais constritas ao local no qual foram produzidas. Essas ameaças, por serem imperceptíveis aos sentidos humanos acabam sendo ingeridas, aspiradas, consumidas, através de ações simples como respirar e ingerir água e alimentos, muitas vezes, contaminados por poluentes industriais.

É neste sentido que as nanotecnologias podem carregar riscos que são gerados pela geração presente, mas que seus malefícios, pela invisibilidade, incerteza científica, transterritorialidade, podem ser suportados por essa geração ou pelas gerações futuras.

O risco pode ser definido por múltiplos conceitos, dependendo da área a ser estudada e devido ao seu caráter multidisciplinar. Para as ciências sociais não é tão simples caracterizá-lo, pois dependendo do contexto pode ter diferentes significados, podendo em modelos estatístico-matemáticos ser compreendida como a probabilidade de um evento gravoso ocorrer (RAMÍREZ, 2009). Já para Beck (2010), de um ponto de vista axiológico, esse termo é muito mais abrangente que o preconizado pela racionalidade científica, uma vez que as ciências objetivamente simplificam o conceito de risco em possibilidades matemáticas e interesses sociais, numa pretensão eminentemente racional. Sendo assim, para o autor, os riscos representariam uma pretensão de dados futuros, mas previsíveis de ocorrer, ou seja, seria uma antecipação de um dano que não ocorreu, mas que pode ser eminente, por esse modo é um risco real atualmente, não se limitando em efeitos e danos ocorridos no passado (BECK, 2010).

Mateiro (2009, p. 178) indica a necessidade de diferenciar os conceitos de risco e perigo, pois não têm o mesmo significado, "desfazendo a sinonímia frequente na linguagem coloquial. Prima facie, o vocábulo risco traz a concepção de provável perigo ou dano futuro". Ademais, essa palavra está relacionada com a probabilidade da ocorrência ou não de um determinado resultado de uma atividade, havendo uma interligação entre risco e probabilidade. Já em relação à palavra improbabilidade, seu conceito relaciona-se com a incerteza, podendo relacionar o vocábulo risco à ideia de incerteza e imprevisibilidade dos eventos. Contudo, a concepção de perigo estaria relacionada com algo externo ao indivíduo, ou seja, uma ameaça externa que se fosse concretizada afetaria a humanidade, tanto em sua integridade quanto em sua 
estrutura social. Portanto, a ideia de perigo estaria relacionada com a compreensão da possibilidade de dano ou prejuízo (MATEIRO, 2009, p. 178).

O risco contemporâneo tem particularidades inéditas: como um grande potencial danoso, dificuldade de precisar sua real extensão e prováveis repercussões, ocasionando sensação de insegurança coletiva, acentuada pelos meios de comunicação em massa. Além disso, entre os grupos de interesses relacionados às novas tecnologias (governo, sociedade civil e indústria), há dificuldade de estabelecer a medida e o grau de intolerância aceitável para uma atividade potencialmente danosa, refletindo-se em discursos antagônicos. Nessa seara, repercute a questão jurídica, pois, muitas vezes, as normas relacionadas a essas questões são ambíguas, são conflitantes entre si e de difícil definição (BOTTINI, 2006).

Para a Comunidade Europeia, a avaliação dos riscos decorre de quatro componentes: a identificação do perigo, a caracterização do perigo, a avaliação de exposição e a caracterização do risco, sendo essa análise influenciada, principalmente, pelos limites do conhecimento científico. A avaliação do perigo consiste em assinalar as causas que podem ter efeitos desfavoráveis na população, através de doenças ou óbito, ou ainda, no meio ambiente (UE, 2000).

Já a especificação do perigo dá-se através da determinação da natureza e gravidade dos efeitos nefastos associados à atividade causal. Nessa etapa, é primordial o estabelecimento da relação entre a quantidade do elemento e seu potencial impacto. A etapa de avaliação à exposição refere-se à avaliação quantitativa ou qualitativa hipótese de exposição à substância em análise. Nessa fase, é prioritária a verificação de dados relativos a possíveis contaminações ou ao possível perigo relacionado à exposição da população ou do ambiente ao agente analisado. Na quarta etapa, há a caracterização do risco relacionado tanto à estimativa qualitativa quanto à quantitativa, tendo em vista as incertezas do potencial ou conhecido efeito danoso sobre o ambiente e a saúde populacional (UE, 2000).

Produtos que empregam nanotecnologia estão disponiveis no mercado consumidor em larga escala e nos mais diversos setores, como: nanofármacos, nanobactericidas, nanotêxtil, nanoalimentos, nanoagrotóxicos, nanobiotecnologia, medicina de precisão, nanoquímicos, entre outros. 0 aumento de produtos disponíveis consequentemente gera o aumento à exposição a essa tecnologia pelo pesquisador, trabalhador e consumidor. Ao lado dos benefícios amplamente divulgados, as nanotecnologias carregam riscos para as presentes e futuras gerações.

Além disso, a falta de regulamentação específica quanto à caracterização da nanotecnologia, ao seu ciclo de vida, tratamento de nanorresíduos, a rotulagem e o manuseio desses produtos, bem como metodologias validadas para a pesquisa responsável para o desenvolvimento de novos produtos nanotecnológicos, exige uma reflexão mais aprofundada sobre como a ciência vem se posicionando sobre os riscos das nanotecnologias. 


\section{METODOLOGIA}

Em relação ao objetivo geral, essa pesquisa assume o nível exploratório e explicativo. Na pesquisa exploratória, busca-se verificar se há uma preocupação dos pesquisadores sobre os riscos da exposição dos seres humanos aos produtos nanotecnlógicos, bem como no ciclo de vida desses nanomateriais, na biodisponibilidade e nos seus efeitos tóxicos, envolvendo artigos científicos publicados sobre a temática. Ademais, o caráter explicativo da pesquisa será analisado com a descrição dos pressupostos que caracterizam a nanotecnologia e os potenciais riscos que podem causar. A pesquisa explicativa aproxima-se da exploratória quando propicia uma nova visão do problema (PRODANOV; FREITAS, 2009).

A técnica de procedimento empregada é a revisão bibliográfica em um dos principais sítios de indexação de trabalhos científicos, Web of Science. Para realizar a revisão bibliográfica, utilizou-se a metodologia de análise de conteúdo desenvolvida por Bardin (2011), que indica para a organização da análise três fases cronológicas: a pré-análise, a exploração do material e o tratamento dos resultados obtidos e a interpretação.

A pesquisa foi realizada nos idiomas inglês e português. Na fase da pré-análise, a análise de conteúdo na base de dados da Web of Science é realizada através da busca isolada das seguintes palavras-chaves: nanotecnologia e nanotechnology, nanotoxicologia e nanotoxicology, além do cruzamento das palavras nanotecnologia e risco, nanotechnology and risk. Já na fase de exploração do material, realiza-se mais um refinamento na pesquisa com o cruzamento entre as palavras nanomaterials and toxicity e das palavras nanoparticles and toxicity, a fim de verificar se houve um aumento de interesse dos pesquisadores com as questões de toxicologia. A seleção dos trabalhos indexados foi delimitada aos últimos cinco anos, ou seja, de 2013 a 2017. Nesta fase, foram escolhidos alguns artigos científicos que tratavam especificamente de nanotoxicidade e riscos das nanotecnologias para a saúde humana e meio ambiente para a realização de leitura mais aprofundada. Por fim, na última fase, buscou-se interpretar os dados obtidos permeando com o olhar da ciência sobre risco, perigos e toxicidade de materiais nanoengenheirados.

\section{RESULTAdos e discussão dos Resultados}

A pesquisa no Sítio da Web of Science foi realizada em novembro de 2017. Utilizou-se como análise dos resultados as categorias disponibilizadas pela Web of Science.

Em relação à palavra nanotecnologia (nanotechnology), foram localizados 14.158 trabalhos indexados nessa base de dados. Verificou-se que os países que mais publicaram trabalhos referentes à nanotecnologia foram os Estados Unidos da América com 26,62\%, seguido da China com 16,18\%, já o Brasil ocupa a $10^{\mathrm{a}}$ posição, correspondendo a 3.779 dos estudos publicados. Quanto às categorias de assunto 
da Web of Science, observou-se que a maior parte delas é relacionada à nanociência e nanotecnologia com $23,63 \%$, ciências dos materiais com $21,08 \%$. As ciências do meio ambiente correspondem a 3, 23\%, enquanto a toxicologia corresponde a apenas 1,63\%, ocupando a $23^{\mathrm{a}}$ opção de interesse.

Quanto à busca isolada da palavra nanopartículas (nanoparticles), apurou-se 294.924 trabalhos, indicando ser uma área de interesse de muitos cientistas. Os países que mais publicaram sobre esse assunto foram a China com 33,56\%, seguido dos Estados Unidos da América com 15,51\%. O Brasil ocupa a $17^{a}$ posição, referindo-se a $1,75 \%$ dos trabalhos indexados. Assim como os resultados acima, a maior parte dos trabalhos associados com nanopartículas são sobre a categoria ciência dos materiais com 27, $34 \%$, química com $20,66 \%$ e físico-química com $19,39 \%$. Já as ciências do meio ambiente compreendem $2,73 \%$ dos trabalhos e, novamente, a toxicologia com 1,09\%. Nessa etapa, surge a categoria de ciência e tecnologia sustentável, correspondendo a $0,73 \%$ dos trabalhos, apesar de ser um número pequeno de publicações, em comparação as outras categorias pesquisadas, pode ser uma área promissora na síntese das nanopartículas.

Com o vocábulo nanotoxicologia (nanotoxicology) aferiu-se 874 trabalhos, com nanotoxicidade (nanotoxicity) apurou-se 764 trabalhos indexados. Já com o cruzamento das palavras nanotecnologia e risco (nanotechnology and risk) verificou-se 664 trabalhos, principalmente dos Estados Unidos da América com $36,29 \%$, seguido da Inglaterra com $8,28 \%$. O Brasil ocupa a $11^{\text {a }}$ posição, correspondendo com $4,07 \%$ das pesquisas sobre esta temática. Realizando uma inter-relação com a quantidade de trabalhos publicados nos últimos cinco anos, observa-se que se manteve praticamente constante o número de publicações, sendo que o ano que teve mais publicações relacionadas com nanotecnologia e risco foi em 2013 com 147 pesquisas.

Na sequência, a intenção é trazer ao texto alguns artigos científicos relevantes para indicar que já há uma preocupação dos cientistas em mapear os riscos do uso de nanotecnologia para a saúde humana e meio ambiente. A escolha dos artigos é aleatória e tem como objetivo apenas mostrar que a nanotecnologia carrega consigo um potencial de risco inimaginável, e que o tema carece de mais estudos.

Inicialmente é preciso dizer que a nanotoxicologia almeja esclarecer os possíveis efeitos nocivos e os mecanismos patogênicos das nanopartículas, tanto para a saúde humana quanto para o meio ambiente. Esses estudos são realizados in vitro e in vivo, todavia, um dos maiores desafios dessas pesquisas é reproduzir em um laboratório a nível experimental as condições naturais (LOURO; BORGES; SILVA, 2013, p. 150).

Muitos desses estudos realizados para avaliar o risco da nanotecnologia nem sempre trazem declarações explícitas sobre os perigos potenciais dessa tecnologia, prejudicando o conhecimento e a 


\section{CONHECIMENTO

transferência de resultados, tanto ao meio acadêmico quanto à população. Devido a isso, cientistas da Dana Incorporated desenvolveram uma base de dados interdisciplinar para armazenar dados e evitar a perda de informações relativa a estudos desenvolvidos com os nanomateriais e as nanotecnologias relacionados com a toxicidade e a influência sobre os seres humanos e o meio-ambiente (KUNEL et al. 2017, p. 1.121-22).

Kunel et al. (2017) analisaram a pesquisa realizada por esses mesmos autores no ano de 2015, indicando que estes pesquisadores disponibilizaram informações de 25 nanomateriais relevantes no mercado, com a indicação da forma de envoltórios a serem utilizadas no material, modo de aplicações e os aspectos tecnológicos. Do trabalho desses autores, Kunel et al. (2017) constataram dados relevantes, entre os quais destacam-se a insuficiência de estudos disponíveis que avaliam os riscos e benefícios da utilização de nanomateriais, por exemplo, dos nanopesticidas em relação aos possíveis danos ao meio ambiente.

A revisão bibliográfica indica que as nanopartículas de dióxido de titânio $\left(\mathrm{TiO}_{2}\right)$, devido a sua versatilidade, são empregadas em diversas áreas, tais como na produção de baterias, na indústria biomédica, em alimentos, construção civil, produtos de higiene, beleza e cosméticos. Além disso, suas características físico-químicas como antibactericida, contra radiações ultravioletas e fotocatalíticas permitem aplicações variadas, sendo essas partículas abundantemente utilizadas. Contudo, esse uso indiscriminado indica um significativo potencial de risco intencional, principalmente para os trabalhadores e pesquisadores dos laboratórios que apresentam maior exposição a essas nanopartículas do que os consumidores em geral. Devido a isso, vários trabalhos estão analisando os riscos que a exposição a esse nanomaterial pode ocasionar à saúde humana (SONG et al. 2016).

Vários estudos, tanto in vitro quanto in vivo, realizados em animais, relataram terem encontrado nanopartículas de dióxido de titânio em órgãos, como cérebro, pulmão, coração e fígado, em fetos e placentas de ratos, após exposição. Com esses dados, sugere-se que a exposição contínua levaria a uma deposição gradual no organismo, causando efeitos tóxicos e disfunções orgânicas. Através dessas pesquisas, foram observados danos celulares como a apoptose, indução de estresse oxidativo, indução de resposta inflamatória e autofagia descontrolada. Todavia, o mecanismo de ação aos danos celulares pelas nanopartículas de dióxido de titânio ainda não foi elucidado, carecendo de mais estudos (SONG et al. 2016).

Esses também foram os resultados encontrados por Gajewicz et al. (2012), na revisão realizada com o objetivo de verificar o estado atual de conhecimento sobre os riscos de nanopartículas sintetizadas. Nessa revisão, constatou-se que as nanopartículas de óxido metálico, tais como óxido cúprico (CuO), 


\section{CONHECIMENTO

dióxido de titânio $\left(\mathrm{TiO}_{2}\right)$, óxido de zinco (ZnO), estão relacionadas com o aumento intracelular das espécies reativas de oxigênio e, consequentemente, com a oxidação de biomoléculas, danos ao DNA, aumento da peroxidação lipídica e diminuição dos níveis de antioxidantes celulares.

As informações expostas acima são bastante preocupantes para a saúde dos consumidores desses produtos, posto que o estresse oxidativo ocorra, quando a quantidade de espécies reativas de oxigênio (ROS) e de espécie reativas de nitrogênio (RNS) são superiores à capacidade de sequestrá-las pelos antioxidantes do organismo, como as enzimas g/utationa peroxidase e superóxido dismutase. Por conseguinte, essas espécies reativas são associadas a danos celulares, inclusive ao DNA, relacionadas a doenças como Alzheimer, síndromes metabólicas, entre outras (JONES, 2016). Ressalta-se que o estresse oxidativo é normalmente gerado em processos bioquímicos realizados pelo organismo, sendo o mais comum a respiração, contudo, os organismos vivos possuem sistemas antioxidantes capazes de controlar esses radicais livres. Todavia, por algum desequilíbrio, pode haver o aumento na geração dessas espécies reativas de oxigênio e ou nitrogênio (FERREIRA; MATSUBARA, 1997).

Outros autores, como Louro, Borges e Silva (2013), estabeleceram a relação da exposição aos nanomateriais e o aumento da geração de espécies reativas de oxigênio, ocasionando lesões nos tecidos e, por conseguinte, no genoma, podendo favorecer o surgimento de câncer. Esse tipo de reação celular em resposta à interação entre as nanopartículas e os tecidos tem orientado os cientistas a estabelecer analogia com os casos de doenças já conhecidas, como a silicose e a asbestose, nas quais a inflamação celular crônica também pode levar à genotoxicidade, às mutações, à morte celular e ao cancro. Nesse estudo, observou-se correspondência no tamanho e na forma fibrosa dos asbestos e dos nanotubos de carbono, ocasionando alerta entre os cientistas quanto à segurança desse nanomaterial; contudo, estudos relacionados a essa questão ainda são inconclusivos (LOURO, BORGES, SILVA, 2013).

Sufian et al. (2017, p. 68) constataram que a distribuição e a eliminação desses nanomateriais no corpo humano podem influenciar nos efeitos tóxicos e são dependentes da sua natureza e propriedade. 0 tamanho da nanopartícula influencia no potencial de penetração nos organismos vivos e, consequentemente, nos efeitos tóxicos, pois quanto menor a partícula, maior é sua reatividade, devido aos fenômenos de superfície. Nanopartículas de tamanho igual ou menor do que $35 \mathrm{~nm}$, conforme estudos, são capazes de permear a barreira hematoencefálica, enquanto que nanopartículas de até 100 $\mathrm{nm}$ podem transpassar a membrana celular. Assim, através dessas informações, eles concluíram que os nanomateriais são mais suscetíveis de causar danos celulares do que a matéria em estado original.

Para finalizar a discussão sobre os resultados da pesquisa realizada na base de dados da Web of Science, é importante trazer o artigo de Johnston et al. (2012), que analisaram os primeiros dados da 
Comissão Europeia de avaliação da segurança dos principais nanomateriais disponíveis comercialmente e verificaram algumas limitações na realização de pesquisas sobre a nanotoxicidade. Primeiramente, a grande quantidade de nanopartículas e uma pequena proporção delas em análise para avaliação de segurança. Ainda, geralmente, essas nanopartículas apresentam variadas características físicoquímicas, sendo necessárias várias técnicas para avaliar suas toxicidades, gerando testes com baixa reprodutibilidade e impossibilidade de padronização. Outro dado importante relatado por Gajewiz et al. (2012) é que há vários métodos de síntese e purificação de nanomateriais, podendo gerar contaminantes que contribuem sinergicamente para a toxicidade. Ademais, as características dos nanomateriais tendem a se modificar de acordo com o lote e o fornecedor, dificultando conclusões em relações aos perigos desses materiais.

\section{CONSIDERAÇÕES FINAIS}

Verificou-se, pela pesquisa realizada na base de dados da Web of Science, que a maioria dos artigos sobre nanotecnologia publicados entre os anos de 2013 a 2017 são relacionados à estabilidade e processo de síntese de novas nanopartículas, entretanto, são poucos os estudos publicados, nessa base de dados, relacionados com a análise da toxicidade das nanopartículas.

Outra importante constatação da revisão bibliográfica realizada está na denúncia de alguns autores de que os estudos realizados sobre a toxicidade das nanopartículas engenheiradas evidenciam divergências sobre a nanotoxicidade de uma mesma nanopartícula. Dito de outro modo, enquanto alguns estudos demonstram que determinadas nanopartículas podem ser altamente prejudiciais ao organismo humano ou ao meio ambiente, existem estudos que mostram que a mesma nanopartícula investigada por outro pesquisador tem baixa toxicidade.

Também foi constatada a carência de protocolos com metodologias validadas para analisar a toxicidade das nanopartículas. Em relação a protocolos e metodologias já publicadas, constatou-se, nos artigos analisados, a crítica dos pesquisadores em relação à baixa reprodutividade destas por outros cientistas que manipulam as mesmas nanopartículas, o que dificulta a validação de metodologias.

Os estudos realizados indicam que os riscos das nanotecnologias estão relacionados às suas características físico-químicas, como tamanho, forma, área superficial, grande variedade e diversidade de nanomateriais desenvolvidos, entre outros. $O$ tamanho da nanopartícula é fator que amplia a toxicidade.

Por fim, os pesquisadores que desenvolveram estudos sobre a toxicidade e os riscos de produtos e aplicações com nanotecnologia indicam a necessidade de ampliação de estudos que avaliam a exposição aos nanomateriais no médio e no longo prazo, bem como estudos que monitorem os riscos em todas as 
fases do ciclo de vida dos nanomateriais produzidos, a biodisponibilidade e os efeitos tóxicos. A indicação dos pesquisadores não é no sentido de paralisar o avanço das nanotecnologias, mas sim de indicar que os laboratórios de pesquisa que lançam produtos com nanotecnologias deverão realizar pesquisas de monitoramento das nanopartículas no organismo humano e no meio ambiente. 0 corpo humano absorve nanomateriais pela inalação, ingestão e pela via transdérmica, e elas viajam livremente pelo organismo gerando novas doenças ou potencializando doenças já instaladas. Por isso a necessidade de observar como as nanopartículas são absorvidas pelo organismo humano, distribuídas, metabolizadas e eliminadas, como elas reagem com outras nanopartículas e outros materiais.

\section{REFERÊNCIAS}

AGÊNCIA BRASILEIRA DE DESENVOLVIMENTO INDUSTRIAL (ABDI). Cartilha sobre Nanotecnologia. Brasília, 2010, p. 20. Disponível em: <www.abdi.com.br/Estudo/Cartilha\%20nanotecnologia.pdf>. Acesso em: 10 mar. 2018.

AGÊNCIA BRASILEIRA DE DESENVOLVIMENTO INDUSTRIAL (ABDI). Panorama de Nanotecnologia. Brasília, 2010. Disponível em: <www.abdi.com.br/Estudo/Panorama\%20de\%20Nanotecnologia.pdf>. Acesso em: 10 mar. 2017.

AGÊNCIA BRASILEIRA DE DESENVOLVIMENTO INDUSTRIAL (ABDI). Relatório de Nanotecnologia. Relatório de Acompanhamento Setorial. Nanotecnologia na Área da Saúde, Mercado, Segurança e Regulamentação. Brasília, 2013. Disponível em: <www.abdi.com.br/Estudo/relatorio-nanotecnologia. pdf >. Acesso em: 10 mar. 2018.

ALLIANZ CENTER OF TECHNOLOGY (ACT); OECD INTERNATIONAL FUTURES PROGRAME. Small sizes att matter: Opportunities and Risks of Nanotechnologies. 2005, p. 6. Disponivel em: <http://www.oecd. org/science/nanosafety/44108334.pdf>. Acesso em: 06 mar. 2018.

BARDIN, Laurence. Análise de Conteúdo. Tradução de Luís Antero Reto, Augusto Pinheiro. São Paulo: Edições 70, 2011.

BECK, U. Sociedade de Risco: rumo a uma outra modernidade. Traduzido por Sebastião Nascimento. São Paulo: Ed. 34, 2010. 
BOTTINI, P. C. Princípio da precaução, direito penal e sociedade de risco. Revista Brasileira de Ciências Criminais, v. 61, p. 44-121, jul./ago. 2006.

CHOI, J.; RAMACHANDAN, G.; KANDLIKAR, M. Policy Analysis. The Impact of Toxicity Testing Cost on Nanomaterial Regulation. Environmental Science \& Technology, v. 43, n. 9, p. 3030-3034, fev. 2009. Disponivel em: <DOI:10.1021/es802388s>. Acesso em: 03 mar. 2018.

COSTA, J. D. S. Síntese e Caracterização toxicológica de diferentes tipos de nanopartículas de Ouro.

Estudos in vitro e in vivo. 2105. 150 p. Dissertação (Mestrado em Controle de Qualidade da Faculdade de Farmácia) - Universidade do Porto. Universidade do Porto, Porto, Portugal, 2015.

DIMER, F. A.; FRIEDRICH, R. B.; BECK, R. C. R.; GUTERRES, S. S. Impactos da nanotecnologia na saúde: produção de medicamentos. Química Nova, São Paulo, v. 36, n. 10, p. 1520-1526, 2013. Disponivel em: <http://www.scielo.br/scielo.phpscript=sci_ arttext\&pid=S010040422013001000007\&Ing=en\&nrm=iso >. Acesso em: 08 abr. 2017.

ENGELMANN, W; MACHADO, V. S. Do Princípio da Precaução à Precaução como Princípio: Construindo as Bases para a Nanotecnologia Compatíveis com o Meio Ambiente. Revista de Direito Ambiental, São Paulo, v. 69, p. 13-50, jan./mar. 2013.

ENGELMANN, W.; HOHENDORFF, R. V.; FROHLICH, A. V. K. Das Nanotecnologias aos Nanocosméticos: Conhecendo as Novidades na Escala Nanométrica. In: ENGELMANN, W. (Org.). Nanocosméticos e o Direito à Informação. Erechim: Deviant, 2015.

FARAJI, A. H.; WIPF, P. Nanoparticles in cellular Drug Delivery. Bioorganic \& Medicinal Chemistry, v. 19, p. 2950-2962, 2009. Disponível em: <https://doi.org/10.1016/j.bm>. Acesso em: 10 mar. 2018.

FERREIRA, A. L. A.; MATSUBARA, L. S. Radicais livres: conceitos, doenças relacionadas, sistema de defesa e estresse oxidativo. Revista Associação Médica Brasileira, São Paulo, v. 43, n. 1, p. 61-68, mar. 1997. Disponivel em: <http://dx.doi.org/10.1590/S0104-42301997000100014>. Acesso em: 10 mar. 2018.

GAJEWICZ, A.; RASULEV, B.; DINADYALANE, T. C.; URBASEZEK, P. ; PUZYN, T.; LESZCZYNSKA, D.; LESZCZYNKI, J. Advancing risk assessment of engineered nanomaterials: Application of computational approaches. Advanced Drug Delivery Reviews, v. 64, p. 1663-1693, 2012. Disponível em: <doi:10.1016/j.addr.2012.05.014>. Acesso em: 10 dez. 2017. 
HOM, A. G. Negociar el Riesgo. Una propuesta para La gestión de riesgos em sistemas tecnológicos complejos. 2004. 730 p. Tese (Doutorado em Direito) - Universidade Autônoma de Barcelona, Barcelona, dez. 2004.

INTERNACIONAL RISK GOVERNANCE COUNCIL (IRG). Appropriate Risk Governance Strategies for Nanotechnology Application in Food and Cosmetics. Genebra, 2009. Disponivel em: <http://www.irgc. org/IMG/pdf/irgc_nanotechnologies_food_and_cosmetics_policy_brief.pdf>. Acesso em: 09 mar. 2017.

JOHNSTON, H. et al. Engineered nanomaterial risk. Lessons learnt from completed nanotoxicology studies: potential solutions to current and future challenges. Critical Reviews in Toxicology, v. 43, p. 1-20, 2013. Disponível em: <DOI:10.3109/10408444.2012.738187>. Acesso em: 20 dez. 2017.

JONES, D. P. Redefining oxidative stress. Antioxid Redox Signal, v. 8, p. 1865-1879, 2006. Disponível em: <doi.org/10.1089/ars.2006.8.1865>. Acesso em: 03 set. 2017.

KUNEL, D. MARQUART, C.; NAU,K; KRUG,K.; PAUL, F.; STEINBACH, C. Environmental benefits and concerns on safety: communicating latest results on nanotechnology safety research - the project DaNa ${ }^{2.0}$. Environmental Science and Pollution Research, p. 11120-1125, 2017. Disponível em: <DOI 10.1007/s11356-016-6217-0>. Acesso em: 02 set. 2017.

LOURO, H.; BORGES, T.; SILVA, M. J. Nanomateriais manufaturados: novos desafios para a saúde pública. Revista Portuguesa Saúde Pública, Lisboa, v. 31, n. 2, p. 145-157, dez. 2013. Disponível em: <http:// dx.doi.org/10.1016/j.rpsp. 2012.12.004 >. Acesso em: 30 set. 2017.

MARKET SPOTLIGHT. Nanotechnology Market to Reach \$64.2 Billion in 2019. Advanced Materials \&Processes, fev. 2015. Disponivel em: <file://C:/Users/Usuario/Downloads/Nanotechnology_market_ to_reach.PDF>.Acesso em: 23 jul. 2017.

MARTINEZ, D. S. T; ALVES, O. L. Interação de Nanomateriais com Biossistemas e a Nanotoxicologia: na Direção de uma Regulamentação. Ciência e Cultura, São Paulo, v. 65, n. 3, p. 32-36, jul. 2013. Disponivel em: <http://cienciaecultura.bvs.br/scielo.php?script=sci_ arttext\&pid=S000967252013000300012\&Ing=en\&nrm=is>Acesso em: 03 out. 2017.

MATEIRO, M. J. M. S. 0 Direito (Auto) monopoiético na Sociedade Cosmopolita de Risco. 2009. $247 f$. Tese (Doutorado em Direito) - Universidade do Vale dos Sinos, São Leopoldo, RS, 2009. Disponível em: <www.dominiopublico.gov.br/download/teste/arqs/cp133026.pdf>. Acesso em: 02 nov. 2017. 
MEDEIROS, E S.; PATERNO, L. G.; MATTOSO, L. H. C. Nanotecnologia. In: DURAN, N.; MATTOSO, L. H. C.; MORAIS, P. C. (Org.). Nanotecnologia: Introdução preparação e caracterização de nanomateriais e exemplos de aplicação. São Paulo: Artliber, 2006.

PINGE-FILHO, P. Pontos quânticos: aplicações em imunologia e relevância para uso clínico. Sociedade Brasileira de Imunologia, 2012. Disponivel em: <http://sbi.org.br/pontos-quanticos-aplicacoes-e/>. Acesso em: 15 jan. 2018.

PRODANOV, C. C.; FREITAS, E. C. Metodologia do Trabalho Científico: Métodos e Técnicas de Pesquisa e do Trabalho Científico. Novo Hamburgo: Editora Feevale 2009.

RAMÍREZ, O. J. Riesgos de Origen Tecnológico: Apuntes Conceptuales para Una Definición, Caracterización Y Reconocimiento de las Perspectivas de Estudio Del Riesgo Tecnológico. Revista Luna Azul, n. 29, p. 82-94, jul./dez., 2009. Disponível em: <http://www.scielo.org.co/pdf/luaz/n29/n29a08>. Acesso em: 28 nov. 2017.

RAUSCHER, H.; ROBBEN, G. Towards a Review of the EC Recommendation for a definition of the term "nanomaterial": part 1: compilation of information concerning the experience with the definition. Joint Research Centre Institute for Health and Consumer Protection, mar, 2014, p. 30-31. Disponivel em: <http://publications.jrc.ecc.europa.eu/repository/bitstream/111111111/31515/1//bna26567enn.pdf>. Acesso em: 14 jan. 2018.

ROYAL SOCIETY \& ROYAL ACADEMY OF ENGINEERING (RSRAE). Nanoscience and Nanotechnology: opportunities and uncertainties. Reino Unido, 2004. Disponível em: <http://www.nanotec.org.uk/report/ Nano\%20report\%202004\%20fin.pdf>. Acesso em: 08 mar. 2018.

SHATKIN, J. A. Nanotechnology: Health and Environmental Risks. 20. ed. Boca Raton: CRC Press, Taylor \& Francis Group, 2013.

SINGH, N. A. Nanotechnology Innovations, Industrial Applications and Patents. Environmental Chemistry Letters, v. 15, p. 185-191, 2017. Disponivel em: <DOI 10.1007/s10311-017-0612-8>. Acesso em: 19 jan. 2018.

SONG, B. et al. Contribution of oxidative stress to $\mathrm{TiO}_{2}$ nanoparticle-induced toxicity. Environmental Toxicology and Pharmacology, v. 48, p. 130-140, 2016. Disponivel em: <http://dx.doi.org/10.1016/j. etap. 2016.10.013 >. Acesso em: 18 fev. 2018. 
SUFIAN, M. M.; KHATLAK, J.Z.K.; YOUSAF, S. Safety issues associated with the use of nanoparticles in human body. Photodiagnosis and Photodynamic Therapy, v. 19, p. 67-72, 2017. Disponível em: <http:// dx.doi.org/10.1016/j.pdpdt.2017.05.012>. Acesso em: 24 set. 2017.

UNIÃO EUROPEIA. Comissão das Cominidades Europeias (Com). Comunicação da Comissão relativa ao princípio da precaução. Bruxelas, fev. 2000. Disponivel em: <https://publications.europa.eu/en/ publication-detail/-/publication/21676661-a79f-4153-b984-aeb28f07c80a/language-pt>. Acesso em: 13 fev. 2018.

VANCE, M. E.; KUIKEN, T.; VEJERANI, E. P. ; MCGINNIS, S. P. ; HOCHELLA JR, M. F.; RYESKI, D.; HULL, M. $\mathrm{S}$. Nanotechnology in the real world: Redeveloping the nanomaterial consumer products inventory. Belistein Journal of Nanotechnology, v. 6, p. 1769-1780, 2015. Disponivel em: <https://www.ncbi.nlm. nih.gov/pubmed/26425429 >. Acesso em: 19 fev. 2018.

WALKER, N. J.; BUCHER, J. R. A $21^{\text {st }}$ Century Paradigm for Evaluating the Health Hazards of Nanoscale Materials? Toxicological Sciences, v. 10, n. 2, p. 251-254, mai. 2009. Disponível em: <dói:10.1093/ toxsci/kfp106>. Acesso em: 24 fev. 2018.

ZARBIM, A. J. G. Química de (Nano) materiais. Química Nova. São Paulo, v. 30, n. 6, p. 1469-1479, nov./dez. 2007. Disponivel em: <http://www.scielo.br/scielo.php?script=sci_ arttext\&pid=S0100-40422007000600016>. Acesso em: 15 nov. 2017. 